\title{
Understanding the Factors that Impact the Pre-Launch Phase and New Product Launch Excellence in the Pharmaceutical Industry
}

\author{
Magdy Rabea \\ Department of Medical Affairs, Sanofi Genzyme, Jeddah, Saudi Arabia \\ Email: Magdyrabea1288@gmail.com
}

How to cite this paper: Rabea, M. (2022). Understanding the Factors that Impact the Pre-Launch Phase and New Product Launch Excellence in the Pharmaceutical Industry. American Journal of Industrial and Business Management, 12, 88-122.

https://doi.org/10.4236/ajibm.2022.121007

Received: December 16, 2021

Accepted: January 27, 2022

Published: January 30, 2022

Copyright $\odot 2022$ by author(s) and Scientific Research Publishing Inc. This work is licensed under the Creative Commons Attribution International License (CC BY 4.0).

http://creativecommons.org/licenses/by/4.0/

\begin{abstract}
Background: The pharmaceutical industry began to rely heavily on new product development looking for achieving an excellent NPL process. That's why, pharmaceutical marketing started to emphasize the pre-launch phase for the pharmaceutical products and began to apply many strategies, tactics, and activities to ensure launch readiness and successful market understanding and acceptance. Existing literature that elicits theoretical and empirical evidence regarding the pre-launch phase and its impact on the launch readiness is limited. Purpose: This research aims to identify the key success factors that impact the excellence of the new product launch process in the pharmaceutical industry. Methodology: A theoretical framework was developed from existing relevant literature then tested and empirical research was conducted using qualitative analysis technique via interviews with experts from the pharmaceutical field to get their insights. Findings: The findings indicate that there are 7 factors that are impacting the excellence of the NPL process. These factors are cross-functional collaboration, market analysis, pre-launch medical activities, pricing strategies, early access programs, human resources allocation and supply chain management strategies. In addition to that the excellence measures have been stratified into qualitative measures, like customer acceptance and gaining high advocacy level of KOLs, and quantitative measures that represent the financial success of the drug in terms of rapid market penetration, gaining MS and the magnitude of MS gain. Limitations: The sample size was small and such a small sample size directed the sampling technique to be purposive sampling which may impact the representation of the total population. Moreover, the empirical data were influenced by the existing factors supposed by literature. Practical Implications: Planning and emphasizing on prelaunch phase is crucial for the excellence of NPL. Moreover, considering the 7 mentioned factors is important for ensuring the qualitative and quantitative suc-
\end{abstract}


cess of the new product introduction to the market.

\section{Keywords}

New Product Launch, Pharmaceutical Marketing, Pre-Launch Phase, Launch Excellence, Launch Readiness

\section{Introduction}

The new product launch refers to the concept of providing a product to the market for the first time and an effective product launch is a critical driver of an organizational top performance (Di Benedetto, 1999), however, it's considered as one of the most complicated marketing processes (Amsbaugh \& Pitta, 2006). The new product launch represents a more specific view on the market entry of a new product compared to the broader concept of commercialization (Sandberg \& Aarikka-Stenroos, 2014).

The pharmaceutical industry always relies extensively on R\&D in their NPL process, delivering the highest ratio of $\mathrm{R} \& \mathrm{D}$ investment to net sales. "The research-based pharmaceutical industry can play a critical role in restoring Europe to growth and ensuring future competitiveness in an advancing global economy. In 2017, it invested an estimated $€ 35,200$ million in R\&D in Europe" (European Federation of Pharmaceutical Industries and Associations, 2018). The successful new drug launch will pave the way for a pharmaceutical company's performance, and accordingly, it enables R\&D for new products in the future (Terblanch, 2008). That illustrated the importance and the positive impact of NPL for the pharmaceutical companies that always seek to find new ways to manage this increasingly challenging and complex context.

Pharmaceutical companies have encountered many challenges over the past decades. (Stros \& Lee, 2015: p. 318) stated, "despite the massive investment in pharmaceutical research, the industry is experiencing significant problems of decreasing productivity".

So, the new drug development process continues to become very challenging in the pharmaceutical industry due to many reasons, for instance, high cost of the new drug development process, Food and Drug Administration's (FDA) regulatory regime, competition from generic drugs, the low success rate for different types of products in development, the product lifecycle management, the patent protection, adverse economic conditions, fast-changing technology in addition to the consumers' expectations regarding drug efficacy and safety that have continued to increase (Terblanch, 2008; Sisodia, 2014).

Pharmaceutical products are different from other non-pharmaceuticals in different terms. (Terblanch, 2008) showed the difference between the new drug development processes and their differences and complexities in comparison to the traditional new product development process as shown in Table 1. 
Table 1. Typical new product development process in the pharmaceutical industry.

\begin{tabular}{cl}
\hline Pre-clinical studies & Step 1: Screening for new clinical entities \\
Pre-clinical studies & Step 2: Discovering of new chemical entities \\
Pre-clinical studies & Step 3: Animal pharmacology: toxicity and re-productivity \\
Pre-clinical studies & $\begin{array}{l}\text { Step 4: Toxicity studies: embryo-fetal and perinatal: } \\
\text { mutagenicity and carcinogenicity }\end{array}$ \\
Pre-clinical studies & Step 5: Chemical, pharmaceutical and biological testing \\
Clinical studies & Step 6: Phase I: bio-availability: healthy volunteers. \\
Clinical studies & Step 7: Phase II: dose ranging-patents \\
Clinical studies & Step 8: Phase III: safety and efficacy \\
Clinical studies & Step 9: Launch \\
\hline
\end{tabular}

Adapted from (Terblanch, 2008).

Due to the complicated and costly new drug development process, the rate of innovation has been decreased and a lot of new drugs that have been approved are similar to existing drugs on the market. (Sisodia, 2014) discussed that in the discovery phase, scientists may start with 5000 to 10,000 different compounds of which only about 250 make their way into the pre-clinical testing to the animal studies and laboratory studies. Of those 250 that enter the pre-clinical testing, only about five are going to eventually be studied in the clinical trials. Throughout the three phases of clinical trials the company is in constant communication with the FDA and at the end submits the NDA, where only about one of those five drugs will ultimately be approved for use in humans. In addition to that, (Dimasi \& Grabowski, 2007) found that most of the new drugs introduced to the market failed to cover their investment costs. As per (Sisodia, 2014) we can find that the cost of developing new drugs has been increased from 100 million dollars in 1991 to be around 1.8 to 2 billion at the time of the article in 2014. On the other hand, (Terblanch, 2008) argued that the spending on R\&D does not necessarily refer to new drug success and there is no significant relationship between a firm's R\&D spend and corporate success. That illustrates that the success of the new drug introduction into the market became very crucial for all pharmaceutical companies to cover all the time, cost and effort spent in the new drug development process.

Based on these tackles and challenges, (Sisodia, 2014) justified the decrease in the development of new molecular entities which refer to the new drug classes. Whereas to mitigate such challenges, (Terblanch, 2008) discussed that the present sales and marketing model needs to be modified to fit these challenges. For instance, success in the primary care market counts on the focus of the current marketing approach whereas a specialist approach is required for targeted treatment solutions that cover both primary and secondary care markets.

Due to changing business environment, the pharmaceutical industry began to rely heavily on new product launches looking for achieving an excellent product 
launch, rapid market penetration and high customer acceptance. That's why, pharmaceutical marketing started to emphasize the pre-launch phase for the pharmaceutical products and began to apply many strategies, tactics, and activities to ensure launch readiness and successful market understanding and acceptance.

This research focuses on the prescription drugs market which is an interesting market to study because of its unique characteristics, such as the high regulation and complex relationships (Stros \& Lee, 2015).

Despite the fact that excellence in the new drug launch has become more popular within the pharmaceutical industry, there is comparatively limited research within this field. Moreover, studies focusing on eliciting theoretical and empirical evidence regarding the pre-launch phase and their impact on the launch readiness are limited.

The launch process can be categorized into five launch phases: launch planning, launch preparations, internal introduction, external introduction, and launch evaluation (Lehtimaki, 2012). On the other hand, the pre-launch duration from the medical affairs perspective was discussed by (Tyson, 2010) within their report in the Pharmaceutical Commerce magazine. They argued that medical affairs launch includes activities for market planning and preparation with a duration ranging from 12 to 24 months prior to the actual launch.

As discussed by (Kuester, 2012: p. 32), "it is pivotal to understand the factors that can be addressed in the market launch to increase the likelihood of new product success".

The main idea is to identify the key success factors of new product launch success, examine their role and impact on launch performance along with evaluating the excellence measures of the NPL process. It's the research about the key success factors that impact the readiness of the new product launch in the pharmaceutical industry.

The structure of the research is arranged as follows. The research starts with a thorough review of the existing NPL literature relevant to the research topic. Based on the holistic overview of the NPL literature, a theoretical framework was drawn. Then, the methodology describes the research method, sampling, data collection and analysis techniques. Then, the key empirical findings are summarized and discussed followed by the final discussion, recommendation and key implications section that conclude the theoretical contributions of the research to the existing NPL literature as well as suggesting avenues for future research.

\section{Literature Review}

The new product development process became vital for every organization in a highly competitive context. Researchers studied that about $60 \%$ of the products launched considered to be commercially successful (Griffin, 1997). Best practice firms realize 49 percent of their sales from new products that have been launched 
in their last five years and these new products' performance accounts for about one fourth of the variability in organizational performance ((Griffin, 1997) cited in (Langerak, 2004)).

In the pharmaceutical industry, the new drug development process is very challenging due to decreased success rates, long development times, high capital requirements, and high level of uncertainty in sales and marketing estimates (Blau et al., 2004). Providing all these challenges, (Terblanch, 2008) recognized that Pharmaceutical companies were pressured to develop new promising products in order to benefit and regain its earlier respectability and profitability. This research also discussed the complexities and high cost of producing new product in the pharmaceutical industry which is different from other industries. Whereas the launch phase for a new product has been estimated with the time period from approximately 2 years before to 2 years after regulatory approval for marketing, also known as the peri-approval period (Evens \& Sylvestri, 2007).

(Matikainen et al., 2015) also highlighted that 2 out of ten marketed drugs succeed to match or exceed their average R\&D costs before losing patents. That's why pharmaceutical companies emphasized heavily on the new product launch success and the rapid market penetration and revenues in a limited timeframe before patent protection ends and competition from generics begins. Building on these points, the successful launch of new drug paves the way towards successful commercialization process and product performance.

\subsection{Research Gaps}

The pre-launch factors that impact the pre-launch phase of the pharmaceutical product and that have an influence on their launch excellence have not been well studied and established in the literature. We can find that the recent literature which discusses the success factors for drug launch readiness is limited. More specifically, the literature on NPL is highly fragmented and there is no holistic or comprehensive approach on key determinants of launch excellence, which most probably, has not yet been discussed.

(Kuester et al., 2012), argues that Introducing new products represents a critical challenge for managers, the article also discussed relationship between different types of market launch activities and its impact on market related, time related, and financial market launch success. The research highlighted that different types of market launch activities can be targeting the internal stakeholder such as internal management and sales personnel, as well as the external stakeholders.

Whereas empirical evidence emphasizing a comprehensive research on how pharmaceutical companies actually rely on internal factors and external factors in the NPL setting remains limited, demonstrating an evident need for further academic study. Thus, numerous gaps still exist regarding the holistic approach on studying factors that are important in the pre-launch setting for the NPL context. 
However, some factors have been solely discussed through literature in the pharmaceutical industry and determined to be having a role in the launch readiness. Using these previously discussed internal and external factors, the theoretical framework has been built while keep providing an emphasis on researching the other factors that also have impact on launch excellence from the participants' point of view.

Although, as discussed, there is a vital need for successful product launches in the pharmaceutical industry, most of pharmaceutical marketing literature have mainly concentrated on product superiority and old fashioned and traditional sales and marketing activities, neglecting the pre-launch phase and the holistic approach of the factors impacting such phase. Accordingly, there is a clear need to research holistically the key factors impacting NPL success (Table 2).

\subsection{Overview and Summary of the Relevant Literature}

The NPL literature review presents two different theoretical approaches, the internal approaches and the external factors that impact launch readiness. The internal factors were the factors that are influencing the internal stakeholders for instance; management, operations and sales employees, for them to be ready for launching the new pharmaceutical products. Whereas the external activities that are impacting the external stakeholders were also discussed in different terms; like traditional sales and marketing activities in the post launch setting, strategic orientations and relationship approaches.

Table 2. Research gaps, research questions and study aim.

\begin{tabular}{|c|c|c|}
\hline Research gap & Research question & Research aims \\
\hline $\begin{array}{l}\text { Limited literature for the } \\
\text { pre-launch phase in NPL in } \\
\text { the pharmaceutical industry. }\end{array}$ & $\begin{array}{l}\text { What is the importance of } \\
\text { the pre-launch phase for } \\
\text { the new product } \\
\text { development in the } \\
\text { pharmaceutical industry? }\end{array}$ & $\begin{array}{l}\text { Deep understanding of the } \\
\text { pre-launch phase in the new } \\
\text { product development in the } \\
\text { pharmaceutical industry. }\end{array}$ \\
\hline $\begin{array}{l}\text { The fragmented NPL } \\
\text { literature focusing on } \\
\text { Pre-launch phase. }\end{array}$ & $\begin{array}{l}\text { What are the pre-launch } \\
\text { factors that have impact } \\
\text { on the pre-launch phase? }\end{array}$ & $\begin{array}{l}\text { Researching recent factors } \\
\text { and activities that are } \\
\text { important for the } \\
\text { pre-launch phase. }\end{array}$ \\
\hline $\begin{array}{l}\text { Limited literature discussed } \\
\text { some factors individually } \\
\text { and their individual impact } \\
\text { on launch excellence in the } \\
\text { pharmaceutical industry. }\end{array}$ & $\begin{array}{l}\text { What are the } \\
\text { comprehensive internal } \\
\text { and external activities that } \\
\text { impact launch excellence? }\end{array}$ & $\begin{array}{l}\text { Providing a holistic and } \\
\text { comprehensive approach } \\
\text { on the key determinants of } \\
\text { launch excellence. }\end{array}$ \\
\hline $\begin{array}{l}\text { Due to the limited literature } \\
\text { discussing the pre-launch } \\
\text { phase in the pharmaceutical } \\
\text { industry, there was limited } \\
\text { focus on lunch excellence and } \\
\text { launch readiness. }\end{array}$ & $\begin{array}{l}\text { How can we evaluate the } \\
\text { pre-launch success which } \\
\text { leads to launch readiness } \\
\text { and excellence? }\end{array}$ & $\begin{array}{l}\text { Providing illustration for } \\
\text { the success of the } \\
\text { pre-launch phase and the } \\
\text { readiness of pharmaceutical } \\
\text { product to be launched in } \\
\text { an excellence way. }\end{array}$ \\
\hline
\end{tabular}


(Kuester et al., 2012), discussed the different types of market launch activities and its impact on launch success, the research argues that launch activities can both target the external stakeholders, for example, via communication and pricing, and addresses the internal stakeholders as well, such as management and sales personnel via using departmental coordination or employee incentives. Interestingly, the research concluded that organizational factors and antecedents indeed play a vital role in new product launch and its respective performance with internally directed activities having an even stronger impact on time-related and financial success.

In addition to that, the product centered approach was well represented in the NPL literature stream especially in other non-pharmaceutical industries, the literature focuses on innovation and the concept of product advantage, product superiority and new class setting. The product advantage was discussed as the benefits that customers receive from a new product in relation to the competitors already present in the market (Calantone \& Di Benedetto, 1988; Henard \& Szymanski, 2001), concentrating mainly on uniqueness, creativity and the innovative characteristics of the new product. Moreover, product advantage has been recognized as an important factor and it has been considered as the customer's perception of product superiority with respect to quality, cost-benefit ratio, or function relative to competitors (Montoya-Weiss \& Calantone, 1994). The product advantage, referred to be as an innovative perspective in the new product launch related literature, supporting the hypothesis that launch performance is directly proportional to providing better products for customers.

On the other hand, while searching the relevant literature in the pharmaceutical industry, the literature discussed individual factors or actions and the impact of each factor on the pre-launch phase. Five Factors have been Identified as important for launching new drug, (Lehtimaki, 2012), discussed the importance of cross-functional exchange of information during the new product development stage. The cross-functional collaboration during launch is considered a vital factor that could contribute to developing an organized approach to launch readiness.

Moreover, Early Access Programs have been discussed as important factor in the pre-launch phase especially in the pharmaceutical industry (Balasubramanian et al., 2016; Bates, 2008; Patil, 2016). In addition to the former both factors, new drug pricing has been discussed as vital for launch readiness and launch success (Calantone \& Di Benedetto, 2007; Di Benedetto, 1999; Kuester et al., 2012; Matikainen et al., 2015). Pricing strategies and policies were considered important either for pharmaceutical or non-pharmaceutical products. In addition to the prelaunch activities which became an evolving factor that impact launch readiness in the pharmaceutical industry, especially the role of medical affairs in the pre-launch phase which was discussed in the literature (Evens \& Sylvestri, 2007; Matikainen et al., 2015; Setia et al., 2018). Finally, Market Analysis as customer awareness, Market intelligence (Matikainen et al., 2015) and the role of Market research (Greene, 2007) as an important prelaunch determinant of the launch ex- 
cellence.

On the other hand, recognizing the readiness or excellence measures in the new product launch was very important. The term excellence is subjected to expectations and may reflect the achievement or exceeding of the pre-set milestones or goals. NPL excellence, or even the alternative term of launch readiness or good performance, would be described as the result of a completely new product development project and can be measured in both short and long term parameters (De Brentani et al., 2010). Launch performance was also discussed as, "the ability of a new product or innovation to avoid failure in the marketplace" (Paladino, 2007: p. 541)

\subsection{Theoretical Framework}

These factors have been used as the backbone of the research along with conducting empirical search on the other factors that could be seen as impactful for the pre-launch phase.

In the Theoretical Framework, factors that are important for the pre-launch phase are divided into two divisions: the internal stakeholders' part and the external stakeholders' part. The identified internal stakeholders' related factor from the literature was the cross-functional collaboration as an aspect that's described as marketing function's information exchange with other functions during the different phases of the launch process (Lehtimaki, 2012). Whereas the external factors were represented in the literature by the Early Access Programs, Market Analysis, Pricing Strategy and the Pre-Launch Market activities that are conducted either by medical affairs or other related functions either for improving the awareness on disease or for any other objectives which pave the market for the introduction of the new product. These factors form the core backbone of the prelaunch phase. In addition, identification of other relevant factors, that are uncovered via literature, is considered during primary research. The research highlights the contribution of these factors to the readiness of new product launch and the excellence in the launch process. Moreover, the excellence and success measures of the launch process in the pharmaceutical industry were identified by the literature to be related to the financial success and customer acceptance (De Brentani et al., 2010; Matikainen et al., 2015; Paladino, 2007). These measures will represent the base for new drug launch excellence along with the other relevant measures that will be identified through the primary qualitative research. The theoretical framework is represented in Figure 1.

\subsection{Cross-Functional Collaboration}

NPL has been described it as the following:

“... It is a multifaceted cross-functional process involving varied information exchange" (Lehtimaki, 2012: p. 31).

Cross-functional exchange of information and alignment between different functions in the organization within the pre-launch phase can be considered as critical success factor for the readiness of the NPL. It is pivotal to illustrate the 


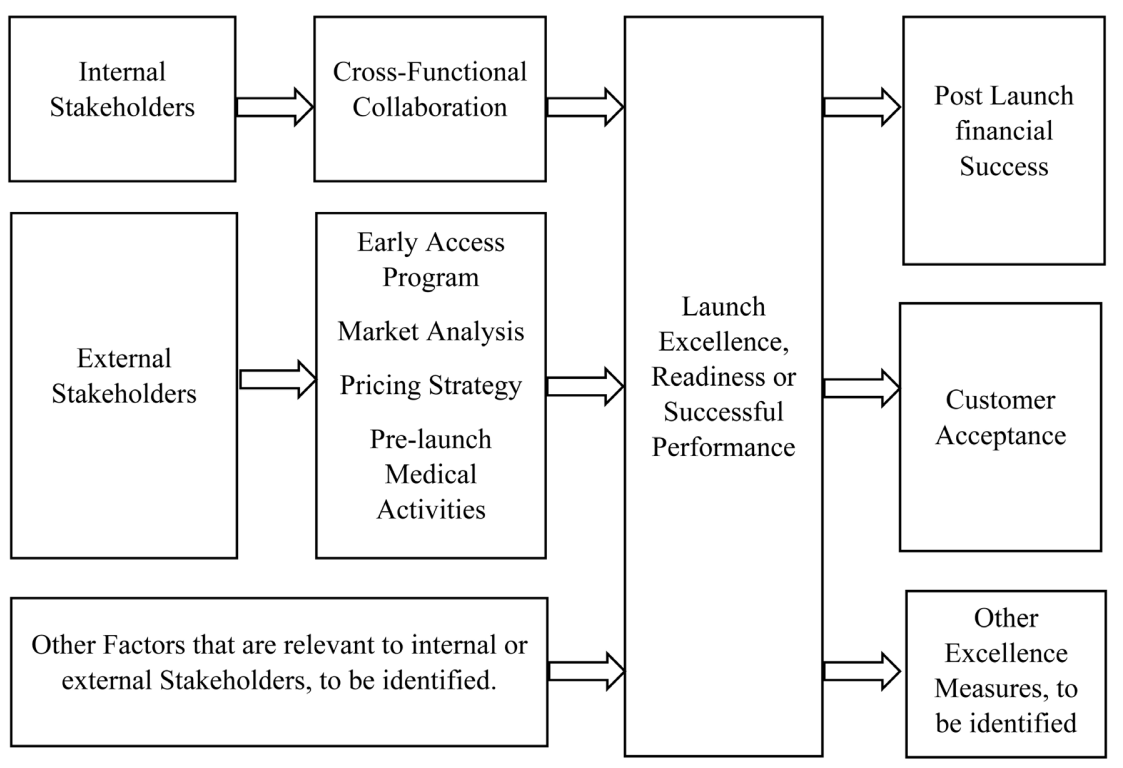

Figure 1. Theoretical framework.

importance of such inwardly directed activities which considered as organizational factors and are targeted to the management and employees involved in organizing and facilitating market launch who can be considered as equally or sometimes more important than external stakeholders. Moreover, some previous research discussed the importance of internal organizational contribution of the internal sales force to the success in launching new products (Atuahene-Gima, 2003; Rochford \& Wotruba, 1996). They found that internal sales force support and readiness have a positive impact on new product sales performance.

Furthermore, the main objective for (Kuester et al., 2012) work was to investigate the two types of launch activities conjointly to assess the relative effectiveness of externally directed activities for example, via communication, promotion, and pricing, and internally directed launch activities addressing the internal audience such as the management, internal employees and sales personnel using tools such as departmental coordination, top management support and the impact of all these activities on new product success.

"The successful launch of new products is a complex task that necessitates the implementation of internally directed launch activities. Fast market penetration requires coordination among the different internal players as well as support from top management" (Kuester et al., 2012: p. 47).

The results of the research that has been conducted on 178 new products across industries (including pharmaceuticals) provided empirical evidence that market launch success depends on the intensity of both externally directed and internally directed launch activities.

Moreover, (Lehtimaki, 2012), deep dived into the importance and role of crossfunctional alignment. This study argued marketing function's information exchange with other functions during the different phases of the launch process. The research contributed to launch management and cross-functional communication 
during NPL.

This study argued that a launch is a challenging phase because it occurs near the end of the NPD project and due to its multi-faceted that involves a variety of information exchange. The study also suggested a new approach to the phasing of the launch process, including an internal introduction phase before the external introduction of the new product.

"Launch management should pay attention to cross-functional information exchange, especially during launch planning, preparations and tests, and launch evaluation, due to the intensive nature of information exchange at those phases" (Lehtimaki, 2012: p. 39).

In conclusion, several functions and departments should be involved in launch planning to align together the necessary information and to commit other parties to the launch plan.

\subsection{Early Access Programs}

In the current marketing, medical and economic environment, pharmaceutical companies are seeking different ways to nurture the launch of new products and produce rapid market penetration. One of these ways is the Early Access Programs. (Bates, 2008) emphasized on the financial impact of using a pre-launch named patient programs, which considered part of the early access tools, on a product launch. The study demonstrated that implementing pre-launch named patient programs had a significant effect on the market share of a drug within the first year of launch.

Moreover, (Patil, 2016) discussed Early Access Programs as an important prelaunch factor that offers ethical, compliant, and controlled mechanisms of access to new investigational drugs before their commercialization, to patients with life-threatening diseases having no treatment options available in addition to the development of positive relationships with Key Opinion Leaders (KOLs), patients, advocacy groups and regulators, which build advocacy base for the product. The research also highlighted other advantages of access programs in the pre-launch phase, as they provide treatment access for patients who cannot take part in clinical trials, for severe cases, sometimes access to the investigational drug is the only option available and can be lifesaving in many cases, They are also implemented when the drug is approved in one country but not in another country where it is needed and requested by terminally ill patients and also they are important when there is a delay in the commercial launch of a drug.

That's why, many companies and specifically in life threatening diseases consider pre-launch Early Access tools as an essential component of their global market access strategy to nurture product launches, produce real life forecasting data and deliver early access to patients.

On the other hand, although Early Access Programs are important, there are many challenges on their implementation in the pre-launch phase. For instance, pharmaceutical companies cannot actively promote for the named patient pro- 
grams due to the unlicensed nature of the drug. This limits the use of traditional pharmaceutical industry communications. Moreover, these programmes also require physicians to complete paperwork and approvals that may be found as being tedious (Bates. 2008). That's why, companies have to develop a coordinated plan for each programme to simplify the process, and work closely with patients, healthcare professionals to make Early Access Programs feasible.

\subsection{Pre-Launch Medical Activities}

The role of medical affairs in the pre-launch phase became crucial, it is not only marketing activities that matters in the NPL phase in the pharmaceutical industry, Nowadays, the medical affairs led activities with the healthcare community became crucial for paving the way for launching the new drug (Evens \& Sylvestri, 2007; Setia et al., 2018).

(Evens \& Sylvestri, 2007) argued that Medical affairs has different strategies in the pre-launch period, the first strategy is enhancing the number, quality and contribution of clinical trials' investigators.

"Investigators will become thought-leaders in the medical community on how this product will enhance therapy and fit into the health care system. Investigators also will be customers who will prescribe the product and recommend its use" (Evens \& Sylvestri, 2007: p. 751).

The second one is identifying the medical needs of the customers in the primary indication of the new drug in terms of research, awareness and education. The third one is publication planning which is a major strategic driver of the whole company, and must incorporate the product's research needs, marketing needs, and characteristics of the health care system into one plan. Fourthly, supporting the marketing plan with the proper and accurate data produced from the company's studies and medical activities and ensuring the quality of such data for a proper marketing plan for the new product. Fifthly, research needs transition to a new phase for with follow-on studies. Sixthly, the proactive risk assessment plan for the areas of marketability risks and alternative risks. Finally, ensuring organizational readiness for the launch.

To implement tactics that achieve medical strategies in the launch period, medical affairs began to establish connections with health care professionals and providing education about potential individualized therapeutic options. In essence, through the field based medical personnel who are called Medical Science Liaisons (MSLs) (Nell, 2018).

The main role for the medical affairs in the pre-launch phase is to engage KOLs in different medical activities. KOL refers to an external medical expert, who is well-recognized within the medical community and valued by his colleagues and has a significant influence on his/her peers. The opinion leaders can be classified into clinical leaders and market leaders based on their specific expertise in a certain therapy or disease area and strong clinical research experience (Matikainen et al., 2015). While their status as leaders can be based on tight 
connections to local physician communities (Stremersch \& Van Dyck, 2009). There is limited number of existing studies on the importance and role of opinion leaders in pharmaceutical market, however, the involvement of KOLs is crucial for the market penetration of a new drug.

The pre-launch medical activities that are conducted by the field based medical teams involves interactions with KOLs for scientific exchange of information, engaging KOLs in several medical activities like speaker events and advisory boards, in addition to internal activities that ensure internal stakeholders' readiness for launch (Chin, 2007; Evens \& Sylvestri, 2007; Matikainen et al., 2015).

\subsection{Pricing Strategy}

Launch time and price are important determinant of the NPL success, launch timing and launch price have an important impact on the pharmaceutical company's bottom line (Verniers et al., 2011). However, the literature discussing the pricing process in the new launches in the pharmaceutical industry was also limited. Regulatory bodies in each country have to review and approve the new drug, then, after scientific approval, the company negotiates with local health authority for gaining market access, typically at the country level. But lastly, company and health authority should agree on launch time and launch price, even though they may have opposite interests (Verniers et al., 2011).

Pricing of new drugs differs from country to another; for instance, the launch price of Pfizer's statin Lipitor was $€ 0.60$ in France, whereas the launch price of that same pill was $\$ 3.98$ in USA (Capell, 2003 cited in Verniers et al., 2011) and it may face challenges in some countries than others based on the reimbursement policy. That's why, the role of pricing and product cost effectiveness should be emphasized (Matikainen et al., 2015; Terblanch, 2008). However, firm regulations that streamline healthcare costs became in place in most countries. The United Kingdom, Japan and Canada began to adopt new criteria for pricing and prescription which exceeds safety and efficacy evaluations, drugs are also now evaluated in respect of their cost effectiveness. Moreover, some regulatory bodies, like in the European Union and Japan, have adopted new regulations to reduce drug prices. For instance, the reference pricing process that has been introduced by the European Union (Terblanch, 2008). On the other hand, Pharmaceutical companies rely on pricing and early access to compensate R\&D costs and gaining higher profitability so they may rationally prefer to delay or take a non-launch decision rather than accepting a relatively low price (Danzon et al., 2005; Wagner \& McCarthy, 2004).

(Verniers et al., 2011) had an interesting research about how launch window, which refers to the difference between the first worldwide launch and the subsequent launch in a specific country, and launch price are interrelated and how the pre-discussed regulations impact launch window and launch price. The research found that launch price has a U-shaped effect on launch window, whereas launch window has an inverted U-shaped effect on launch price. In depth, the 
fastest launch occurs when the launch price is moderately higher. The research also found that regulation lengthens the launch window. But on the contrary to expectations, regulations don't directly influence launch prices, however, they may reduce the launch price over time.

Generally, pricing strategy became an important determinant for the NPL success and to emphasize on such importance, (Terblanch, 2008: p. 208) stated, "all regulatory reviews will include an assessment of the cost-effectiveness of new drugs, and approval will be contingent on satisfying this criterion in addition to demonstrating safety and efficacy".

\subsection{Market Analysis}

Understanding Market is a basic, crucial and critical factor, and its absence may lead to the NPL failure or no launch decision, not only for the pharmaceutical industry but also for many products. (Matikainen et al., 2015: p. 184) stated: "the managers launching a new drug should focus on comprehensively gathered market intelligence".

That shows how market intelligence is important. One of the market intelligence assets is the information gathering tactics throughout the NPL process. Information typically becomes more valid and reliable as the NPL process moves forward toward commercialization (Di Benedetto, 1999). Market intelligence is a broader concept which includes consideration of exogenous market factors, for instance; competition and regulations that affect customer needs and preferences, and current as well as future needs of customers (Kohli \& Jaworski, 1990).

There are several information gathering activities that can be used for market analysis like marketing research, Market surveys (Di Benedetto, 1999; Greene, 2007) and advisory boards with KOLs to get their insights for prober market understanding from the key market drivers (Gupta \& Nayak, 2013; Setia et al., 2018).

Market analysis, especially through marketing research, began to be fundamental activity in any phase of the product lifecycle. It covers constant observation of the entire medical and pharmaceutical horizon, so that the physicians' prescription habits can be thoroughly analyzed (Greene, 2007). Such analysis will be the building block for the marketing strategy and pre-launch marketing plan. Therefore, careful execution of market research and market analysis activities is required to obtain key insights about customers, disease management and competition along with the effectiveness of the marketing activities that also can be undertaken to provide feedback both during and after launch (Di Benedetto, 1999).

Moreover, the medical advisory boards are also considered as very important tool for market analysis. Therefore, (Setia et al., 2018: p. 778) stated, "medical advisory boards provide pharmaceutical companies with valuable insights on various topics, ranging from trial protocols to regulatory submissions. Advisory boards can be held at any stage during product development and facilitate the generation of data, the development of products, and the creation of trustworthy edu- 
cational content".

Market intelligence has been determined, long time ago, as the starting point for marketing of new products especially in the pharmaceutical industry. That's why, using market analysis tools within the pre-launch phase is critical.

\subsection{Launch Excellence Measure}

Measuring NPL excellence and good new product performance is tricky and requires further evaluation. A holistic evaluation of launch performance involves customer acceptance and financial performance measures (Matikainen et al., 2015). The customer adoption of a new product is the base of improvement in financial performance, while poor customer acceptance, in the contrary, is a reason for NPL failure.

"Lack of support from the adoption network is found to be an especially critical cause of failure for systemic innovations" (Chiesa \& Frattini, 2011: p. 437).

Whereas financial success measure for launch performance refer to the overall attainment of financial launch targets relating to sales, market share and profitability (Di Benedetto, 1999; Homburg \& Pfesser, 2000; Montoya-Weiss \& Calantone, 1994 cited in Matikainen et al., 2015). Giving such importance for the customer acceptance, especially the KOLs segment, along with financial measures vitality for NPL, the role and influence of key factors affecting launch excellence should be studied from both customer acceptance and financial success perspectives (Berndt et al., 2002). Therefore, it is considered worthwhile to discuss these two areas of NPL excellence.

\section{Methodology}

This study is the results of completion of the author's master dissertation. The new product launch excellence research outlined in this article was developed from both secondary and primary sources. As this research aims to highlight the main factors impacting the pre-launch excellence as well as the excellence measures, it was necessary to have a deep and thorough review of the relevant literature highlighting the same topic. That's why, it was an iterative methodology which began with a comprehensive search of the literature focusing on the new product launch in the pharmaceutical industry. Since there is a clear gap in the literature for this topic, it was important to involve and review all key research articles arguing this topic irrespective of research time to formulate the theoretical framework. Then the secondary data that have been found in the literature, have been used as the starting point of the research and these data were considered the main backbone for the primary data aimed to be collected. As mentioned before, it was found within the literature that there are factors which are most importantly influencing the new drug launch readiness. These factors are the cross-functional collaboration, pricing strategies, pre-launch activities, market analysis and early access programs. The research focuses on these predetermined factors from previous literature, and then the contribution of these factors to the overall objective 
of launch excellence is analyzed along with other factors that were highlighted during the primary research, which was targeting pharmaceutical companies particularly, prescription drugs sectors.

So, the research problem is answered by systematically combining theory and empirical data based on abductive logic. Some procedures can be used in a deductive basis, the data categories and codes used to analyze data derived from theory and following a predetermined analytical framework (Saunders et al., 2009). First the data were organized according to the existing literature and the primary research. Then the identified data within each broad category were also sub-categorized according to the implications, importance and challenges for applying each factor. In addition to that, the launch excellence measures have been also categorized based on the existing literature and the data gathered during the empirical search. The identified launch process factors and information categories were compared with the literature review. After the data reduction and display, the findings were compared with and linked to the existing knowledge base, and conclusions drawn.

\subsection{Secondary Data (Methodologies of the Relevant Literature)}

The literature studying new product launch strategies relied on both qualitative and quantitative tools, (Di Benedetto, 1999) studied the key success factors in new product launch using quantitative method. The research used mail survey instrument for data collection and the data were measured using 0 to 10 Likerttype scales. Quantitative methods were also used by many researchers in the NPL related topics (Calantone \& Di Benedetto, 2007; Langerak et al., 2004; Matikainen et al., 2015).

Focusing on the most relevant research conducted by (Matikainen et al., 2015), the research also used survey method directed to pharmaceutical companies to study determinants of New Product Launch Success and the data were analyzed via multivariate data analysis methods. So it was important to conduct another qualitative research to complement what has been found in (Matikainen et al., 2015) study. On the other hand, qualitative methods were also adopted by the NPL researchers (Lehtimaki, 2012; Trim \& Pan, 2005). (Lehtimaki, 2012) used semi-structured interviews which were aimed to be free of predefined categorizations or models and to bring forward the perceptions and wording of the interviewees. While (Trim \& Pan, 2005), conducted in-depth personal interviews and a focus group sessions which involved managers within a pharmaceutical company. The researcher used the unstructured, in-depth interview method, to allow the respondents to express their opinions in a spontaneous manner. While the main idea behind adopting the focus group method was that the members of the group will discuss a specific topic under the guidance of the researcher to provide valuable insights for various subject matters.

\subsection{Research Design (Qualitative Research)}

A qualitative strategy has been adopted in the research through semi-structured 
in-depth interviewing method. The interviews with research participants included predefined themes which was relevant to the existing literature. The research aimed for getting a thorough overview about the current practices in the NPL process within the pharmaceutical industry, hence, the qualitative methods and specifically in-depth interviews tool has been adopted for such reason. The personal interview method can be used to gather data and insights to answer specific questions and to probe where necessary, hence achieving a better understanding of the subject matter (Patton, 1980; Trim, 1998 cited in (Trim \& Pan, 2005)). The unique characteristics of the pharmaceutical industry require industry specific knowledge as well as, the comprehensive objective of the research required getting insights and opinions of industry specific experts to build the final conclusion about the determinants of NPL excellence.

Summarization, categorization or structuring techniques either on their own or in combination can be used to analyze or interpret qualitative data (Saunders et al., 2009). The researcher has adopted combination of such techniques while analyzing data using the predefined relevant categories. In addition to that, the categories suggested during the interviews have been employed to code, to identify themes and trends and that helped the researcher to elaborate and provide and organize the insights of the interviewees.

\subsubsection{Data Collection}

The interviews have been conducted with 10 experts from the pharmaceutical field to get insights about the influence of these factors and the challenges that companies are facing to implement such determinants along with what other factors that impact successful new launch implementation. It was planned to have participation of 7 participants due to the time limits and across countries participants distribution however, the researcher managed to reach interviewees with 10 experts. The interviews evaluated the importance and current adoption status of such factors in implementing new launch and the excellence measure of NPL. The interviews included predefined frame based on existing literature and the main aim was to bring forward the perceptions, insights wording of the experts. It was particularly interesting to gain insights about the current state of practice in the NPL process and to validate the predefined theoretical framework empirically.

Several steps were used for data collection to complement the research design to provide proper results and recommendations, as shown in Table 3.

\subsubsection{Sample}

The research design nature was to include small number of planned participants. So, the researcher has chosen the purposeful sampling technique. Purposeful sampling is widely used in qualitative research, Purposive Sampling choose the participants based on relativeness to the research, that's why, it's a useful technique in identifying and selecting the information rich participants pertaining to the research's area of interest. It's also used in accordance with the research 
Table 3. Research design.

\begin{tabular}{|c|c|c|}
\hline Step 1 & Literature review & $\begin{array}{l}\text { The identification of the reference sources } \\
\text { and secondary data that will be used. }\end{array}$ \\
\hline Step 2 & $\begin{array}{l}\text { Literature survey or } \\
\text { literature utilization }\end{array}$ & $\begin{array}{l}\text { The utilization of the reference sources and } \\
\text { the extraction of the relevant information, } \\
\text { aiming for setting a theoretical model. }\end{array}$ \\
\hline Step 3 & $\begin{array}{l}\text { Theoretical } \\
\text { model construction }\end{array}$ & $\begin{array}{l}\text { Construction of the theoretical framework that is } \\
\text { relevant to the existing literature and applicable } \\
\text { for the pharmaceutical industry. }\end{array}$ \\
\hline Step 4 & $\begin{array}{c}\text { Primary } \\
\text { data collection }\end{array}$ & $\begin{array}{l}\text { Using qualitative research method, the } \\
\text { in-depth personal interviews tool, to gather } \\
\text { empirical data about the predefined model } \\
\text { as well as expanding the empirical data } \\
\text { beyond the existing theoretical model. }\end{array}$ \\
\hline Step 5 & Data analysis & $\begin{array}{l}\text { Analyzing primary data to get results in } \\
\text { order to provide recommendations and } \\
\text { define the implications. }\end{array}$ \\
\hline Step 6 & Reflections & $\begin{array}{l}\text { Overall evaluation of the research and } \\
\text { providing the challenges along with } \\
\text { the research limitations. }\end{array}$ \\
\hline
\end{tabular}

objective and research questions (Saunders et al., 2009). However, such techniques may have some limitations for instance; it doesn't ensure generalizability of findings and minimizing the potential for bias (Palinkas et al., 2015).

Suitable participants have been identified and evaluated based on their familiarity with new product launch related practices and their years of experience within the pharmaceutical industry. The research sample planned to represent different functions and departments within the pharmaceutical companies. They had to primarily agree to participate in the research, they should have clear understanding of what the research is about and confidentiality assurance. They have been provided with participant information sheet and they had to sign participation consent prior to their participation.

The research included participants who belong to Marketing, Medical Affairs, Market Access and Business Development to provide a multi-perspective picture of the NPL process. The research also included employees from different layers including the senior managers. A comprehensive description of the participant is shown in Table 4. The research also represented pharmaceutical companies in 3 different regions, Egypt, Saudi Arabia and the Gulf region to provide different insights from different countries which have many similarities like culture, level of awareness and timing of the new drug introduction to the market post FDA and EMA approvals. The selection of countries was also based on accessibility to participants in pharmaceutical companies. 
Table 4. Description of research participants.

\begin{tabular}{|c|c|}
\hline Demographics & No. \\
\hline \multicolumn{2}{|l|}{ Country } \\
\hline Egypt & 2 \\
\hline Saudi Arabia & 6 \\
\hline Gulf Affiliate & 2 \\
\hline \multicolumn{2}{|c|}{ Participants' Department in Their Company } \\
\hline Marketing & 3 \\
\hline Medical Affairs & 4 \\
\hline Market Access & 1 \\
\hline Business Development & 1 \\
\hline Sales & 1 \\
\hline \multicolumn{2}{|c|}{ Participants' Position in the Company } \\
\hline Director & 2 \\
\hline Manager & 8 \\
\hline \multicolumn{2}{|c|}{ Participants' Experience in the Pharmaceutical Industry (Years) } \\
\hline $5-10$ & 1 \\
\hline $10-15$ & 7 \\
\hline $15-20$ & 2 \\
\hline
\end{tabular}

\section{Data Analysis}

The first aim of this study was to analyze the Key factors that impact New Product Launch excellence in the pharmaceutical industry along with the key measure of excellence.

The main categories identified were: 1) The emerging criticality of the pre-launch phase in the pharmaceutical industry; 2) The optimum duration required for a successful pre-launch; then 3) the key important elements or factors for the prelaunch phase that have been subcategorized into: a) Cross-functional Collaboration in the NPL process; b) Market analysis (market surveys and market researches) impact; c) The pre-launch tactical activities; d) The early access programs argument; e) Pricing strategies; f) Allocation of resources; g) Supply chain management impact on the launch excellence. Then finally: 4) The key measures for the launch excellence. Questions were assigned within interviews with the participants to rate the importance of each factor in comparison to the others in terms of high, medium or low importance.

These categories have been identified after several reviews, transcriptions and manual coding of the interviews with participants who represented different functions, companies, affiliates and positions. The participants have been referred to them via symbols and numbers that represent the country/region, function and company number. 


\subsection{The Emerging Criticality of the Pre-Launch Phase in the Pharmaceutical Industry}

Last decade, due to the augmented strict regulatory environment in the pharmaceutical industry, interviewees from medical affairs argued that the regulatory framework embarked rules that inhibit promoting drugs before gaining market authorization from the local regulatory bodies. Giving that limitations, MMG3 stated, "... due to the unique regulatory limitations in the pharmaceutical field, the pre-launch phase had unique activities and many challenges as long as new roles and functions began to have important impact on such phase to reach excellent launch".

That also has been confirmed by his emphasis on the emerging role of several functions recently in NPL process like Medical Affairs, Market Access and Regulatory Affairs. The existing literature underpinned the unique characteristics and complex regulations and relationships in the pharmaceutical field (Stros \& Lee, 2015; Terblanch, 2008). The matchless characteristics of the pharmaceutical industry underline the importance of cross-functional collaboration and internal alignment between different functions for a successful NPL process and empowered the emergence of brand teams that will be discussed later.

On the other hand, the criticality of pre-launch phase has shown wider impact, BHSA1 showed that in the pre-launch phase, the management decides either to go for launch or no-launch decision or launch cessation for the new drug. So, we can see that its impact went beyond the excellence in the NPL process, but it also may have impact on the completion of the launch process.

The whole research participants emphasized that pre-launch activities became a prerequisite for new launches excellence. MMSA2 and MASA1 highlighted that earlier, pharmaceutical industry was driven by the production orientation, and they confirmed that the industry began to be driven by marketing activities due to emerging high level of competitions. Participants also highlighted that the industry became more mature as the competition increased and many alternative treatments started to be available to the same indication. NPLSA1 also argued that there became a drainage in the new pipelines for the pharmaceutical companies, hence competition increased. He concluded that the companies showed more focus on the pre-launch phase as companies haven't the enough luxury for failure of their new product launch or even weak introduction into the market. He concluded from such experience that the product lifecycle in the pharmaceutical industry has been extended to include the pre-launch phase as a critical path for new product introduction.

As per MMSA2 and MASA1 arguments that in the old era when the focus on pre-launch period was limited, companies relied heavily on the product advantage and its performance against the standard of care treatments. However, the existing literature argued that product advantage and relationship marketing activities contributed to having the acceptance of key opinion leaders in the early phase of launch, while marketing activities and the relationship orientation found 
that they largely led to the acceptance of the majority of target customers in the later phase (Matikainen et al., 2015). NPLSA1 argued that prior to the emerging NPL process era, activities in pre-marketing authorization and pre-regulatory approval period included participation of physicians in the clinical trials like phase 3 trials.

However, He thinks that only participation in the clinical trials is not enough and further activities are required.

Moreover, participant BHE2 highlighted that pre-launch phase started to be considered in some therapy areas before the others, especially oncology and rare diseases due to high disease gravity. BHSA1 also emphasized that companies started to consider their pre-launch activities with doctors to foresee what is coming up in the pipelines of solutions for such diseases and how the patient will benefit from such new products.

Relaunching concept was also suggested by participants in case of NPL failure, however, there has been a consensus on avoiding relaunching the previously failed products, especially in the pharmaceutical field.

\subsection{The Optimum Duration Required for a Successful Pre-Launch}

The optimum duration for the pre-launch phase was an important concern which required deep discussions with the experts. The pre-launch duration from the medical affairs perspective was discussed by (Tyson et al., 2010) within their report in the Pharmaceutical Commerce magazine. They argued that Medical affairs launch includes activities for market planning and preparation with a duration ranging from 12 to 24 months prior to actual launch.

It was found during the research that pre-launch optimum duration depends on many variables. Primarily, in the multinational pharmaceutical companies the pre-launch duration from the global or regional perspective is longer than what is required for the local affiliates on the national level.

The participants especially BHSA1 and BHE2 highlighted that the pre-launch phase, from the local affiliate's perspective, begins with the decision of the affiliate to launch in coordination with the global or regional entity. It was found that duration also depends on the product itself, for instance; if the product is first in class which requires longer time than second to market products. Moreover, it depends on the market itself, if the market is well developed and the awareness about the disease, new management updates and the treatment options are also well perceived within the therapeutic area market, so the optimum duration for pre-launch phase will be lesser. It also depends on the existence of the company within the relevant market. If the company is having legacy products or enough relations with key stakeholders within the market that may impact the required pre-launch period. It was found that it also depends on the local regulatory authorities' rules for approving and providing market authorization for a new drug.

These variables were found by the primary research that they impact the NPL duration and specifically the pre-launch phase. However, from the discussion with 
the experts and after considering all these variables, the optimum duration was found that it ranges from 1.5 to 2 years on the national level or in other words, from the local affiliate's perspective, and more than 3 years from the regional and global perspective. However, it was also argued that sometimes practically, from the local affiliate's perspective and due to delayed coordination and arrangements between the local and the global levels, the pre-launch duration may deducted to be only 1 year for the local affiliates especially, in Saudi Arabia and Gulf region where regulatory approvals for some drugs started to be faster than before that may require less than 1 year.

On the other hand, some experts argued that no certain timelines or optimum duration should be put in place primarily or planned and we have to begin from the affiliate's decision to launch until we can see that it's the proper time to launch after getting local approvals and fulfilling all required activities that paves the ground for the new drug. However, the existing literature didn't support such proposal.

\subsection{Key Elements or Factors that Have an Impact on the NPL Excellence}

\subsubsection{Cross-Functional Collaboration in the NPL Process}

Despite the importance this research found for the internal cross functional alignment, the literature discussing the same issue were scarce, especially in the pharmaceutical industry. However, the research approached a consensus on how critical is the cross functional collaboration, mainly in the NPL process.

The Cross functional collaboration in the NPL process was described via BHE2, "simply, it's all about aligning all internal departments and functions within the affiliate around one unified goal which is making this new product successful" (BHE2).

Emphasizing on such perspective, the internal stakeholders' involvement was argued by the interviewee as crucial for NPL success. It was also argued by the participants that, the internal stakeholders should buy in the importance and the value of the new product. That's why, the primarily internal introduction of the new product for the internal stakeholder is an essential phase that should be embedded within the NPL process. That's proving what has been discussed via (Kuester et al., 2012) who illustrated that launch activities should be internally directed towards internal employees as well as the externally directed activities. In addition to that (Lehtimaki, 2012) added the internal introduction as an early phase of the five phases of the Launch process.

The interviewees also showed that Cross-functional collaboration isn't limited to the internal introduction phase, in contrast, MKME2 described it as a live interaction between all relevant stakeholders across the organization within the NPL process. He argued that the concept of Brand Team has been emerged in many pharmaceutical companies.

1) Brand Team

Giving the criticality of cross-functional alignment, brand team concept started 
to be embedded in the NPL process. Brand team was described by the interviewees as a team which involves all internal stakeholders and functions that are involved in the internal and external activities in the NPL process. Brand Team members are personnel from several departments like Medical Affairs, Marketing, Sales, Market Access, Regulatory Affairs, and Supply Chain Management.

It was argued that the NPL process are usually moderated by the marketing and business unit head, they may have been considered as the owners of the launch process and the primary responsible for its success. However, the ownership should be embedded between all relevant functions of the brand team to reach the wider objective of the NPL process.

To achieve such alignment, it was argued by the interviewees that the brand team members should gather on timely manner either monthly or biweekly basis in a meeting including all functions together so that things are done smoothly either in parallel or in serial. They have to discuss all the KPIs and what is needed from each one in the team to fulfil those KPIs. We can also find that the literature (Lehtimaki, 2012) highlighted on the diversified information that need to be exchanged between different functions in NPL process.

All interviewees agreed on the high importance of the cross-functional collaboration. They all admitted that it's a crucial part of the NPL process that may be considered as indispensable. We can see here a great matching between the research inputs and the existing literature discussing the importance of the internal organizational factors (Kuester et al., 2012; Langerak et al., 2004) and the role of cross-functional exchange of information in NPL excellence (Lehtimaki, 2012).

\section{2) Challenges that Are Facing Cross-Functional Alignments}

Despite the importance of such factor, the interviewees highlighted on several challenges that may deter the proper application of such collaboration. Firstly, each function has its own nature that differs from other functions. MKME2 illustrated such challenge, he stated, "a marketer would look into the segmentation of the market from a commercial perspective. While the medical affairs personnel will look on the market segmentation from a more scientific perspective, KOLs segmentation, a medical merit and research participation so he doesn't have any commercial view or objective. Furthermore, market access may look into the market from the perspective of payers and reimbursement strategies and activities that would work with the payers".

So, functions have different roles, tasks, regulations and KPIs. Secondly, it was argued by the participants that it's not all about the nature and difference in Job tasks but it's more importantly the difference in the functional objectives and the success in aligning these sub-objectives to serve one goal pertaining to the NPL process as whole. Thirdly, NPLSA1 mentioned that NPL process requires high level of interdependencies between different departments which require high level of cooperation and harmonization. Finally, participants agreed that the crossfunctional collaboration can be done as a routine, but it couldn't be effective un- 
less there is an inspiring spirit within the functions so that all departments should be supporting the launch.

Overall, the cross-function collaboration and inter-departmental alignment during the NPL process was considered of high criticality that considered as the base for the success of whole external factors and it's an essential and indispensable factor that leads to excellence in the NPL process.

\subsubsection{Market Analysis}

It was found during the research that analyzing and understanding the market where the new product will be launched is an essential part of the pre-launch phase. Based on such analysis the brand team will build forward for the pre-launch and post-launch activities. It was also found that the timing of market analysis is very critical in the success of any NPL process. That was expected as such factor is indispensable during the whole product lifecycle, not only for the pre-launch phase and that's agreed with the existing literature.

\section{Market Analysis Tools}

There are many tools for analyzing the market some of them have been discussed via literature like Market research (Di Benedetto, 1999; Greene, 2007) and advisory boards with KOLs to get their insights for prober market understanding from the key market drivers (Gupta \& Nayak, 2013; Setia et al., 2018). It was found that such tools are widely used recently within the pre-launch phase of the pharmaceutical products in order to get market insights for instance; epidemiology and burden of the disease in certain country, patient journey from diagnosis to treatment decisions, available treatment options and the widely adopted treatment paradigms. Such insights help in analyzing the market and planning for the required activities in order to pave the way for the new product. Advisory boards described as a gathering for the most eminent KOLs who have great experience with the disease area in order to get their insights and to reply the company's inquiries without any promotional intent Especially, if the company is planning to enter a new market or a new therapy area in which the pharmaceutical company didn't have any experience before. In addition to that, Advisory boards began to be considered a common tool for getting insights particularly form the disease expertise who can provide a very trusted picture and overview of the market.

Moreover, Medical affairs Interviewees like MMG3, MMSA2 and MMSA4 also highlighted the emerging role of field based medical affairs personnel, MSLs.

"MSLs main role is getting insights during their interactions and activities with HCPs and from the HCPs and specifically the key experts. The MSLs afterwards transfer such insights to the brand team to analyze disease-specific dynamics and recognize the emerging updates and opportunities within the market" (MMSA2).

It was also argued by the interviewees that MSLs have great role in validating any pre-determined information from the market for instance, via market surveys or research. 
Analyzing the market in the pre-launch phase started to exceed the notion of getting insights about the market to recognizing information and perceptions about the product itself prior to registration. BHE2 stated, "there is a very important thing which may be missed from many companies which is the brand equity market research however, you didn't launch the product, but we are living in a small town and people may have a perception about the product as they see its data via internet, international events and published product's clinical data" (BHE2).

So, it's important to make a market research about the perceived value of the drug prior to the launch to aid in directing the pre-launch activities.

\subsubsection{The Pre-Launch Tactical Activities}

Pre-launch tactical activities have been also discussed with the interviewees as a factor for NPL success. It was argued that pre-launch activities are the tools by which brand team pave the way for the new drug introduction into the market. The interviewees highlighted that such activities should involve all the external stakeholders, not only KOLs but also other HCPs, payers and sometimes media to publicize the disease awareness. It was found that these activities are integrated activities that require collaboration from several functions.

\section{1) MSLs Role in the Pre-Launch Activities}

MSLs were described as the field-based arm of the medical affairs department who are responsible for scientific exchange of information with the external medical community for several objectives. Interviewees highlighted that MSLs' main role is executing the medical affairs tactical plan which is aligned with the brand team strategy. Experts highlighted that MSLs began to have great role in NPL process through conducting several activities and interacting with KOLs and HCPs. These activities have been described by MMG5 and NPLSA1 as non-promotional activities that increase disease gravities and identify unmet needs within the market.

Particularly medical affairs participants discussed that the main objectives of pre-launch activities are enhancement the awareness of the disease, understanding the unmet medical need and paving the way for introducing the new drug. The most highlighted activities by the interviewees were advisory boards, conducting scientific forums, preceptorships, the continuous medical education programs which argued by MMG3 that in which the company representative from the medical affairs department or an invited expert disseminates information to improve the awareness of the HCPs. Majority of the mentioned activities are matching what has been discussed via literature (Setia et al., 2018) except preceptorships which became a new area of interest for participants.

\section{2) Missed Key Stakeholders}

It was also discussed by several interviewees that engaging patients in the pre-launch phase is still limited and requires more attention from pharmaceutical companies to gain their valuable insights and advice in certain diseases. Examples of such activities were highlighted by participants like patients' advisory 
boards and sponsoring awareness activities/campaigns that are conducted via medical or patients associations. Such emphasis on patients hasn't been discussed before via literature and it may be the forthcoming area of discussion.

\subsubsection{The Early Access Programs Argument}

It was found that EAPs have several names according to each regulatory framework in each country, for instance; expanded access programs, compassionate use programs, named patient programs and special importation license. The process of EAPs has been described, "as you engage with doctors in disease awareness interaction and they see the unmet medical needs and reactively asking about the new products and when the company answer all the questions, the doctor might be in a position that recommend or prescribe the new drug to patient who really needs for the medication" (MMSA4).

MMSA4 also highlighted that although the product hasn't been registered yet in the country, physicians may need for the drug for some patients especially, in certain diseases where the available treatments are scarce. Several participants argued that the Medical Affairs and Regulatory Affairs teams should work together to be ready in case of EAPs need to be in place. Interviewees also added that several types of EAPs are provided free of charge so the medical lead for the therapy area in each country, in his launching strategy, may allocate part of the budget for EAPs. That agrees with (Bates, 2008) description of EAPs as the ethical ways of making pre-launch medicine available in where the drug still not yet approved.

It was argued by BHSA1 and MASA1 that EAPs may have positive impact especially in the pre-launch phase of the product, they explained that it provides a solution in some situations when there are no enough treatment options. Secondly, EAPs always facilitates the barrier to try the new treatment and provide an opportunity for early penetration into market. Thirdly, it gets the HCPs and payers confident to know value versus the proposed price. We can find that such inputs about the importance of EAPs are matching to great extent the existing literature discussing different types of EAPs and their role in the NPL process (Bates, 2008; Patil, 2016). However, some interviewees argued that EAPs is of low importance and isn't considered as essential factor for the NPL process due to many challenges and legalities issues related to EAPs.

\section{Challenges and EAPs Controversial Issues}

There were controversial opinions about EAPs role in the NPL process. Such debate stemmed from importance, applicability and legalities of EAPs. Regarding the application of EAPs some interviewees discussed that EAPs may be suitable in some treatments with a greater extent than others for instance; oncology treatments where there are high unmet medical need. From different perspective the regulatory issues for EAPs are considered controversial. Interviewees highlighted on some wrong practices that may be fulfilled as companies may push for named patient supply as they use this as gateway for market entry, instead of being a reactive tool that the companies should be prepared for. Moreover, some EAPs 
aren't free of charge so pushing for such programs prior to local regulatory approval of the drug may be having a promotional intent. Accordingly, such practices have been stopped via the compliance regulations, quality audits and inspections from regulatory authority. So, interviewees argued that such programs are controlled by the medical affairs department to ensure that there is no commercial drive. That's why, MMSA2 commented, "it's very tricky and grey area as you've to be prepared for such programs but at the same time you shouldn't push for it".

Giving such limitations, the interviewees had varied opinions whether EAPs are considered as crucial factor, or we cannot rely on such debatable factors for the NPL success.

\subsubsection{Pricing Strategies}

\section{1) Factors Influence Pricing Strategies}

Pricing strategy was described by participants as a complicated step in the launch process, as you are surrounded by different factors like profitability, country regulations, benchmarking with reference countries, acceptance of the patients and the market to the price and ensuring of having good product contribution and most of these factors are out of company's hands.

Participants also highlighted on the correlation between the pricing strategies and the inputs gained from market analysis like (price elasticity research, competitor price, reimbursement strategies). So, MASA1 concluded that measuring pricing elasticity within the market should be an integral part of the pricing exercise as pricing strategies may be applied based on internal perceptions. However, he argued that it's important to measure the market's response to the proposed pricing. That's why MMSA2 highlighted that recently advisory boards for payers started to be part of the pre-launch activities as it's important to test the response from the reimbursement perspective.

The impact of timing on pricing was discussed through literature either for its impact on launch price (Verniers et al., 2011), or due to the reference pricing regulations (Terblanch, 2008). Participants also highlighted on such impact of timing and they focused mainly on the reference pricing, in which the regulatory authorities compare the price proposal by the company with the price of the same product in other countries in which the product has been registered. So, participants highlighted that early pricing agreements with the local authorities will avoid low price countries.

\section{2) Recent Emphasis on Health Economics Outcome of New Drugs}

Nowadays, the real-world evidence and effectiveness factors became pre-requisite. Cost effectiveness is one of these factors due to budget constraints. That has been illustrated as the following, "... now big companies started looking at health economics outcomes research which is a big part of the real-world evidence. Regulatory bodies started to ask for such research to evaluate the cost effectiveness of the new product and its impact on the indirect cost like exacerbations, hospitalization and administration of concomitant medications, and whether it decreases 
the overall healthcare budget or not" (MASA1).

Participants concluded that cost effectiveness and budget impact models became very critical as most of the new innovations directed towards biologics which are very costly, so that the new treatment should have an indirect impact on patient management costs to enhance the payer in the reimbursement decisions.

\section{3) Importance of Pricing Strategies for NPL Success}

Some participants revealed the importance of pricing strategies as one of the determinants for NPL success and they highlighted that companies should have a good plan while negotiation with health authorities in order to get the required price that match company's ambitions. Some others like BHSA1 and BHE2 see that if the price didn't match company's goal that may force the company to have a no-launch decision. On the other hand, 2 participants who are MASA1 and MMG5 see that planning for pricing strategies may be important in some situation in case of high competitive market while it's not with the same importance if the new product is extremely innovative and there is a high unmet need within the market.

\subsubsection{Allocation of Human Resources}

Although Human resources allocation wasn't included within the theoretical framework and the existing literature discussing such issue is scant, Participants recognized it as an important factor that impacts NPL success. NPLSA2 stated, "building the team is $75 \%$ of your success. If you don't have the right team whatever, you do it will not work". Interviewees emphasize also on the criticality of timing of allocation for each function. There was an agreement especially from the business unit heads that medical manager, brand manager and market access employees should be deployed 2 years prior to launch while MSLs 1.5 years and sales team 6 months prior to launch. They also emphasized on sales force readiness starting from hiring the right calibres, diversification between highly experienced and new blood, adding incentive scheme then inspiring and energizing the team.

\subsubsection{Supply Chain Management and NPL Success}

In addition to human resources allocation, it was found that SCM strategies were described by interviewees as very critical for NPL success. BHE1 stated, "if you don't have enough stock for at least 6 months in your warehouse prior to launch, don't go for launch".

That illustrated how SCM is an important determinant for NPL success as sometimes you do all the previously mentioned factors, but the product couldn't be available in a very critical post launch period.

\subsection{The Key Measures for the Launch Excellence}

\subsubsection{Launch Readiness and Launch Excellence}

Interviewees highlighted on the difference between readiness and excellence, “... readiness refers to the regular set of activities that should be done irrespective to 
having the final go for launch or no-go for launch decision. While excellence refers to the effectiveness of such activities that lead to successful new product introduction into the market which measure through qualitative measures and quantitative measures" (NPLSA1).

So, readiness and excellence are correlated, however, you may be ready for launch by fulfilling all the NPL process KPIs and the quality of implementation of such KPIs is what leads to the excellence in the NPL process. Readiness for launch was described by participants as the critical Path for NPL with some checkpoints activities whose fulfilment is crucial before launch. From there, the concept of launch capacity has emerged which is a measure or quantification of fulfilment of critical paths or check points that is essential for the new product introduction. Launch capacity is measured on timely bases either monthly or quarterly.

\subsubsection{Qualitative and Quantitative Measures}

(Matikainen et al., 2015) discussed the determinant of NPL success based on customer acceptance and financial success. Participants agreed on such determinants and they've also categorized such measures into qualitative and quantitative ways for measuring NPL Excellence. They've described quantitative measures as financial success of the new product, rapid market penetration, growing sales values, gaining MS and the magnitude of MS gain. While the qualitative measures were represented by high level of KOLs engagement, KOLs advocacy base for the products, fulfilling launch KPIs and high level of customer acceptance for the value of the new products. Such Qualitative measures were described as intangible that's why, some companies started to evaluate such intangible measures via market researches to test the acceptance of HCPs and KOLs for the new product. One of these researches is the message recall test that evaluate whether the pre-launch activities succeeded to disseminate the planned message or not.

At the end, all participants agreed that having the product launch is a partnership between the company and external stakeholders, if you engage with external stakeholder early on and they saw your commitment, professionality and ethics while uncovering the needs of having your product in the market, they will advocate the importance of having such new solution.

\section{Discussion/Conclusion/Reflections/Recommendations}

\subsection{Discussion}

This research contributes to the existing literature by providing a holistic and comprehensive overview of the key factors that are influencing the pre-launch phase for a successful NPL process. The study broadens the established links between such factors and the NPL success along with providing a balanced and comprehensive review of the influence of each factor on the NPL process. The study also identified new factors that have an influence on the NPL success and haven't been discussed via the existing literature. Moreover, the research dis- 
cusses the determinants and the measures of excellence in launching a new product in the pharmaceutical industry.

Based on reviewing the relevant literature, the theoretical framework has been drawn. The theoretical framework is designed to search for an answer to the research questions and to uncover the research gaps that have been identified. Many gaps have been identified, primarily, limited literature discussing the pre-launch phase in NPL in the pharmaceutical industry. In addition to that, the factors that have been discussed within the literature are fragmented and limited comprehensive or holistic approaches, in addition to the confined focus on the measures of NPL excellence.

Internal and external factors have been solely discussed via literature and determined to be having a role in the NPL process. The external factors in the prelaunch involved Early Access Programs as an important pre-launch factor that offers ethical, compliant, and controlled mechanisms of access to new investigational drugs before the commercialization of the drug, to patients with life-threatening diseases having no treatment options available, pricing strategies and policies (Di Benedetto, 1999; Calantone \& Di Benedetto, 2007; Kuester et al., 2012; Matikainen et al., 2015), the pre-launch activities which became an evolving factor that impacts launch readiness in the pharmaceutical industry; especially, the role of medical affairs in the pre-launch phase (Evens \& Sylvestri. 2004; Matikainen et al., 2015; Setia et al., 2018). Finally, market analysis is as customer awareness, market intelligence (Matikainen et al., 2015) and the role of market research (Greene, 2007) is as an important prelaunch determinant of the launch excellence.

These factors have been considered as the backbone of the research in addition to identifying the other factors that could be seen as impactful for the prelaunch phase.

The research aimed for getting a thorough overview of the current practices in the NPL process within the pharmaceutical industry, hence, the qualitative methods and specifically in-depth interviews tool has been adopted. Interviews have been conducted then transcription, summarization and categorization techniques have been applied to analyze the qualitative data. The interviews have been conducted with 10 experts from the pharmaceutical field to get their insights and to have a deep understanding of the NPL process in order to reply to the research questions.

\subsection{Conclusion, Recommendations and Implication}

\subsubsection{Pre-Launch Phase in the Pharmaceutical Industry}

The pre-launch phase in the pharmaceutical industry had its unique characteristics and factors that have a great influence on the product launch. It's the phase at which management decides either to go for launch or to enact no-launch decisions. Now there is not any luxury for NPL failure so companies put their resources and full emphasis on the pre-launch planning activities. That's why, several functions had emerged roles in the NPL process recently like Medical Af- 
fairs, Market Access and Regulatory Affairs.

It was found through the primary research that the pre-launch phase became recently of high important and high critical for NPL success. It's the gatekeeper for pre-launch success. The pre-launch phase provides full insights for the company about the future direction of the new product. Hence, the main purpose behind the NPL process is to differentiate the product and the company in the earlier stages and to ensure that your product will launch successfully and all resources that you've put in have clearly prepared the market for the launch.

The optimum duration for the pre-launch phase is an important issue that should be put in mind. The pre-launch optimum duration should be set based on many variables, the product itself whether it's a first in class or not, the market whether it's well-developed or not and the existence of the company within the market. However, it's advisable to range from 1.5 to 2 years prior to launch on the national level. While some experts see that no timelines should be pre-set for the pre-launch phase and the product should be launched at any time after fulfilling the pre-launch objectives.

\subsubsection{Factors that Are Influencing the NPL Process}

There are elements and factors that construct the NPL process and have great influence on its excellence. The research concluded that there are 7 factors that are impacting NPL process, 5 of them was drawn within the theoretical framework while 2 others have been identified through the primary research. The factors are cross-functional collaboration, early access programs, pre-launch medical activities, pricing strategies, market analysis along with the 2 newly identified factors, human resources allocation and supply chain management.

Primarily cross function collaboration which found having high criticality and an indispensable factor as it's the base for excellence in the NPL process.

It's a live interaction between all internal stakeholders that are part of the brand team, a recent concept adopted in the NPL process. Brand team involves stakeholders that are representing several functions like Medical Affairs, Marketing, Sales, Market Access, Regulatory Affairs, and Supply Chain Management.

Cross-functional collaboration found to be having a great influence on the NPL excellence. However, there some challenges that have to be overcome for a successful implementation of cross-functional collaboration. Aligning all functional diversities in terms of diverse objectives, natures, and tasks is the basis of achieving such collaboration. Or in other words, despite all diversities and interdependencies, all internal stakeholders have to work under one overall objective which is the NPL excellence.

Moreover, Market analysis has been recognized as one of the foundations of the pre-launch phase. It's the tool that aids the brand team in drawing the NPL strategy. Market research, market surveys and advisory boards are the main tools that are used for getting market insights and analyzing the market. In addition to that, MSLs have great role in gaining market insights during their interactions 
and activities with KOLs. However, New drug details now is readily available through different sources and the future direction is going towards conducting brand equity market research to get the customer perception about the product prior to launching the new drug.

In addition, Medical affairs involvement has been increased recently in the pre-launch phase, not only for market analysis activities like advisory boards and MSLs interactions, but also for the pre-launch medical activities that pave the way for introducing the new product in the market. Particularly, MSLs are now an indispensable part of the NPL process through their activities that aim for improving the awareness of HCPs and uncovering the unmet medical needs within the disease indication in which the new product will be serving. Congresses sponsorship, preceptorship, and continues medical education programs are the main activities that are conducted during the NPL period. On the other hand, companies started to engage patients through their patients' associations within their NPL plan.

Moving forward to another factor which is the EAPs like-named patient program, compassionate use programs and special importation license. The implementation and importance of EAPs have been recognized as controversial. Such programs provide hand on experience of the new drug before its launch which improve and facilitate market penetration. However, the application and legalities of EAPs are questionable that's why, EAPs are always monitored by medical affairs department and externally via regulatory authorities.

Furthermore, Pricing has been determined as an influencing factor for the excellence of NPL. It's a complicated step that is surrounded by many out-of-hand influences. Setting proper pricing strategies relies heavily on market intelligence as inputs derived from market analysis shapes the way the company position its pricing strategy for the new product. Pricing strategies are also time-sensitive due to the reference pricing regulations adopted by health authorities and early agreements with the local authorities on the new product price will deter the risk of other lower price countries. Companies should also consider the health economics outcomes during their strategies for new product pricing as regulatory authorities, payers and KOLs started to emphasize on evaluate the cost effectiveness of the new product and its impact on the indirect cost that are incurred by the country, hospital or patients.

Adding to the previously recognized factors via literature, 2 other factors have been added by the participants for their influence on NPL, the Human Resources allocation and supply chain management. Proper allocation of human resources in terms of timing, quantity and quality is essential for internal readiness for the NPL process. It was found that it's advisable to allocate medical manager, brand manager and market access employees 2 years prior to the launch while MSLs 1.5 years and sales team 6 months prior to launch. On the other hand, it's critical to optimize SCM strategies as the new product supply is very important after especially, directly after its registration in order to get faster market penetration and to avoid any consequence on new product reputation. 


\subsubsection{Evaluation of Excellence of NPL Process}

Key measures for NPL success can be categorized into qualitative and quantitative parts. The qualitative part is something intangible which is pertaining to the customer acceptance of the new drug like the level of KOLs engagement with the company and the level of KOLs advocacy for the new product in addition to another qualitative measure which is the readiness in terms of fulfilling all pre-launch activities and launch KPIs. The quantitative measure was found to be representing financial success of the drug in terms of rapid market penetration, gaining MS and the magnitude of MS gain. Although such quantitative measures are more tangible, it requires appropriate duration after the launch to measure whether the NPL was successful or not.

In conclusion, the overall results are aligned with the existing literature however results show more holistic and comprehensive review. In particular, the findings answered the research questions to great extent and uncovered the research gaps that have been determined prior to the research. However, the research had some limitations that needed to be avoided in future research.

\subsection{Avenues for Future Research}

In addition to the theoretical contributions and recommendations resulted from the research there are some limitations which offer avenues for future research.

The number of participants was small due to time, nature and context of the research being mainly focusing on the pre-launch period in which selective functions are involved. However it's advisable to recruit larger sample in future research. The small sample size directed the sampling technique to be purposive sampling which may not be representative to the total population. In addition to that the gathered data were influenced by the existing factors supposed by literature. The data gathered are influenced by prior theoretical suppositions or ideas which mayn't encourage divergent thinking. It may also limit the possibility of creativity. Moreover, this research focuses mainly on the NPL from the perspective of prescription drugs, while other categories like consumer healthcare drugs and FMCG products in the pharmaceutical industry should be considered.

\section{Conflicts of Interest}

The author declares no conflicts of interest regarding the publication of this paper.

\section{References}

Amsbaugh, P., \& Pitta, D. A. (2006). New Product Introduction at TyRx Pharma, Inc. Journal of Product \& Brand Management, 15, 468-472. https://doi.org/10.1108/10610420610712865

Atuahene-Gima, K. (2003). Adoption of New Products by the Sales Force: The Construct, Research Propositions, and Managerial Implications. Journal of Product Innovation Management, 14, 498-514. https://doi.org/10.1111/1540-5885.1460498 
Balasubramanian, G. et al. (2016). An Overview of Compassionate Use Programs in the European Union Member States. Intractable and Rare Diseases Search, 5, 244-254.

Bates, A. K. (2008). Implementing a Pre-Launch Named Patient Programme: Evidence of Increased Market Share. Journal of Medical Marketing, 8, 319-324. https://doi.org/10.1057/jmm.2008.25

Berndt, E. et al. (2002). An Analysis of the Diffusion of New Antidepressants: Variety, Quality, and Marketing Efforts. The Journal of Mental Health Policy and Economics, 5, 3-19.

Blau, G. E. et al. (2004). Managing a Portfolio of Interdependent New Product Candidates in the Pharmaceutical Industry. Journal of Product Innovation Management, 21, 227-245. https://doi.org/10.1111/j.0737-6782.2004.00075.x

Calantone, R. J., \& Di Benedetto, C. A. (2007). Clustering Product Launches by Price and Launch Strategy. Journal of Business \& Industrial Marketing, 22, 4-19. https://doi.org/10.1108/08858620710722789

Calantone, R., \& Di Benedetto, C. A., (1988). An Integrative Model of the New Product Development Process: An Empirical Evidence. Journal of Product Innovation Management, 5, 201-215. https://doi.org/10.1111/1540-5885.530201

Chiesa, V. and Frattini, F. (2011). Commercializing Technological Innovation: Learning from Failures in High-Tech Markets. Journal of Product Innovation Management, 28, 437-454. https://doi.org/10.1111/j.1540-5885.2011.00818.x

Chin, J. (2007). Measuring Performance of Field-Medical Programmes: Medical Science Liaison Metrics Consensus. Journal of Commercial Biotechnology, 13, 177-182.

Danzon, P. M. et al. (2005). The Impact of Price Regulation on the Launch Delay of New Drugs-Evidence from Twenty-Five Major Markets in the1990s. Health Economics, 14, 269-292. https://doi.org/10.1002/hec.931

De Brentani, U. et al. (2010). Success in Global New Product Development: Impact of Strategy and the Behavioral Environment of the Firm. Journal of Product Innovation Management, 27, 143-160. https://doi.org/10.1111/j.1540-5885.2010.00707.x

Di Benedetto, C. A. (1999). Identifying the Key Success Factors in New Product Launch. Journal of Product Innovation Management, 16, 530-544. https://doi.org/10.1111/1540-5885.1660530

Dimasi, J. A., \& Grabowski, H. G. (2007). The Cost of Biopharmaceutical R \& D: Is Biotech Different? Managerial and Decision Economics, 28, 469-479. https://doi.org/10.1002/mde.1360

European Federation of Pharmaceutical Industries and Associations (2018). The Pharmaceutical Industry in Figures: Key Data 2018. EFPIA.

Evens, R. P., \& Sylvestri, M. (2007). Product Launch and the Strategies, Processes, and Operations of Medical Affairs to Support Start-Up Companies. Drug Information Journal, 41, 743-759.

Greene, J. A. (2007). Pharmaceutical Marketing Research and the Prescribing Physician. Annals of Internal Medicine, 146, 742-748. https://doi.org/10.7326/0003-4819-146-10-200705150-00008

Griffin, A. (1997). PDMA Research on New Product Development Practices: Updating Trends and Benchmarking Best Practices. Journal of Product Innovation Management, 14, 429-458. https://doi.org/10.1111/1540-5885.1460429

Gupta, S. K., \& Nayak, R. P. (2013). An Insight into the Emerging Role of Regional Medical Advisor in the Pharmaceutical Industry. Perspectives in Clinical Research, 4, 186-190. https://doi.org/10.4103/2229-3485.115386 
Henard, D. H., \& Szymanski, D. M. (2001). Customer Satisfaction: A Meta-Analysis of the Empirical Evidence. Journal of the Academy of Marketing Science, 29, 16-35.

Kohli, A. \& Jaworski, B. (1990). Market Orientation: The Construct, Research Propositions, and Managerial Implications. Journal of Marketing, 54, 1-18. https://doi.org/10.1177/002224299005400201

Kuester, S. et al. (2012). Externally Directed and Internally Directed Market Launch Management: The Role of Organizational Factors in Influencing New Product Success. Journal of Product Innovation Management, 29, 38-52. https://doi.org/10.1111/j.1540-5885.2012.00968.x

Langerak, F. et al. (2004). The Impact of Market Orientation, Product Advantage, and Launch Proficiency on New Product Performance and Organizational Performance. Journal of Product Innovation Management, 21, 79-94. https://doi.org/10.1111/j.0737-6782.2004.00059.x

Lehtimaki, T. (2012). Managing the New Product Launch Process: Cross-Functional Information Exchange Perspective. International Journal of Advances in Management and Economics, 1, 31-41. https://doi.org/10.31270/ijame/01/04/2012/06

Matikainen, M. et al. (2015). Determinants of New Product Launch Success in the Pharmaceutical Industry. Journal of Pharmaceutical Innovation, 10, 175-189.

https://doi.org/10.1007/s12247-015-9216-7

Montoya-Weiss, M., \& Calantone, R. (1994). Determinants of New Product Performance: A Review and Meta-Analysis. Journal of Product Innovation Management, 11, 397-417. https://doi.org/10.1111/1540-5885.1150397

Nell, G. K. H. (2018). Medical Affairs. In D. Vohora, \& G. Singh (Eds.), Pharmaceutical Medicine and Translational Clinical Research (pp. 393-399). Academic Press. https://doi.org/10.1016/B978-0-12-802103-3.00026-2

Paladino, A. (2007). Investigating the Drivers of Innovation and New Product Success: A Comparison of Strategic Orientations. Journal of Product Innovation Management, 24, 534-553. https://doi.org/10.1111/j.1540-5885.2007.00270.x

Palinkas, L. A. et al. (2015). Purposeful Sampling for Qualitative Data Collection and Analysis in Mixed Method Implementation Research. Administration and Policy in Mental Health and Mental Health Services Research, 42, 533-544. https://doi.org/10.1007/s10488-013-0528-y

Patil, S. (2016). Early Access Programs: Benefits, Challenges, and Key Considerations for Successful Implementation. Perspectives in Clinical Research, 7, 4-8. https://doi.org/10.4103/2229-3485.173779

Rochford, L., \& Wotruba, T. R. (1996). The Impact of Sales Management Changes on New Product Success. Journal of the Academy of Marketing Science, 24, Article No. 263. https://doi.org/10.1177/0092070396243007

Sandberg, B., \& Aarikka-Stenroos, L. (2014). What Makes It So Difficult? A Systematic Review on Barriers to Radical Innovation. Industrial Marketing Management, 43, 1293-1305. https://doi.org/10.1016/j.indmarman.2014.08.003

Saunders, M., Lewis, P., \& Thornhil, A. (2009). Analysing Qualitative Data. In M. Saunders, P. Lewis, \& A. Thornhil (Eds.), Research Methods for Business Students (pp. 480-525). Pearson Education.

Setia, S. et al. (2018). Evolving Role of Pharmaceutical Physicians in Medical Evidence and Education. Advances in Medical Education and Practice, 9, 777-790. https://doi.org/10.2147/AMEP.S175683

Sisodia, S. (2014). A Review of New Drug Innovation-Emerging Challenges and Mitiga- 
tion Strategies. IOSR Journal of Pharmacy, 4, 43-48.

Stremersch, S., \& Van Dyck, W. (2009). Marketing of the Life Sciences: A New Framework and Research Agenda for a Nascent Field. Journal of Marketing, 73, 4-30. https://doi.org/10.1509/jmkg.73.4.004

Stros, M., \& Lee, N. (2015). Marketing Dimensions in the Prescription Pharmaceutical Industry: A Systematic Literature Review. Journal of Strategic Marketing, 23, 318-336. https://doi.org/10.1080/0965254X.2014.931878

Terblanch, N. S. (2008). New Pharmaceutical Product Development: Barriers to Overcome and Opportunities to Exploit. Journal of Commercial Biotechnology, 14, 201-212.

Trim, P., \& Pan, H. (2005). A New Product Launch Strategy (NPLS) Model for Pharmaceutical Companies. European Business Review, 17, 325-339. https://doi.org/10.1108/09555340510607370

Tyson, G. et al. (2010). Preparing the Market for a New Drug with an Effective "Medical Affairs Launch". Pharmaceutical Commerce. https://www.pharmaceuticalcommerce.com/view/preparing-the-market-for-a-new-dru g-with-an-effective-medical-affairs-launch

Verniers, I. et al. (2011). The Global Entry of New Pharmaceuticals: A Joint Investigation of Launch Window and Price. International Journal of Research in Marketing, 28, 295308. https://doi.org/10.1016/j.ijresmar.2011.05.008

Wagner, J., \& McCarthy, E. (2004). International Differences in Drug Prices. Annual Review of Public Health, 25, 475-495.

https://doi.org/10.1146/annurev.publhealth.25.101802.123042

\section{Key Abbreviations}

NPL: New Product Launch;

FDA: Food and Drug Administration;

EMA: European Medicines Agency;

R\&D: Research and Development;

KOLs: Key Opinion Leaders;

MSLs: Medical Science Liaisons;

KPIs: Key Performance Indicators;

HCPs: Health Care Professionals;

SCM: Supply Chain Management;

MS: Market Share;

FMCG: Fast Moving Consumer Goods;

EFPIA: European Federation of Pharmaceutical Industries and Associations. 